\title{
Financial Depth and the Asymmetric Impact of Monetary Policy
}

\author{
Mustafa Caglayan*, Ozge Kandemir Kocanslan† and Kostas \\ MOURATIDIS
}

*School of Social Sciences, Heriot-Watt University, Edinburgh, EH14 4AS, UK (e-mail: m.caglayan@hw.ac.uk)

$\dagger$ Department of Economics, Hacettepe University, Beytepe Yerleşkesi, 06800 ÇankayaAnkara,Turkey (e-mail: ozge.kandemir@hacettepe.edu.tr)

†Department of Economics, University of Sheffield, Sheffield, S1 4DT, UK (e-mail: k.mou ratidis@sheffield.ac.uk)

\begin{abstract}
This paper investigates the importance of financial depth in evaluating the asymmetric impact of monetary policy on real output over the course of the US business cycle. We show that monetary policy has a significant impact on output growth during recessions. We also show that financial deepening plays an important role by dampening the effects of monetary policy shocks in recessions. The results are robust to the use of alternative financial depth and monetary policy shock measures as well as to two different sample periods.
\end{abstract}

\section{Introduction}

There is a vast body of empirical literature which examines the effects of monetary policy on the real economy. Several researchers in monetary economics have claimed that the impact of monetary policy on the real economy varies over the course of the business cycle. For instance, some researchers, referring to sticky prices and nominal wages, relate the asymmetry to the sign of the monetary policy shocks. ${ }^{1}$ Others have argued, on the basis of menu cost models, that the impact of monetary policy depends on the size of the shock rather than the sign. ${ }^{2}$ Still others, referring to the credit channel, suggest that the asymmetry of monetary policy shocks relates to the state of the business cycle. ${ }^{3}$

There is also a long and well-established research in macroeconomics that shows credit market imperfections play a significant role in magnifying output fluctuations. ${ }^{4}$ The

JEL Classification numbers: E32, E52.

${ }^{1}$ See for instance, Cover (1992), DeLong and Summers (1988) and Karras (1996).

${ }^{2}$ See for instance, Ball and Romer (1990), Ball and Mankiw (1994) and Ravn and Sola (2004).

${ }^{3}$ Among others see, for example, Garcia and Schaller (2002), Lo and Piger (2005) and Dolado and María-Dolores (2006).

${ }^{4}$ See, for example, Bernanke and Gertler (1989), Bernanke, Gertler and Gilchrist $(1996,1999)$. Also see Levine (2005) and Papaioannou (2007) for detailed surveys of this literature. 
literature claims that financial market distortions create a powerful source of propagation by means of a financial accelerator mechanism; that is, an unanticipated adverse (monetary) shock would decrease not only the demand for capital but also the firms' net worth, thereby inducing a further drop in investment and output. Research, therefore, suggests that an economy with deeper financial markets could mitigate the adverse effects of shocks, as innovative firms could continue to draw funds from potential lenders even during economic downturns.

In this paper, we empirically investigate whether monetary policy has asymmetric effects over the course of the business cycle, and the extent to which financial frictions affect the transmission of monetary policy shocks as the economy evolves. Earlier research that has examined the asymmetric effects of monetary policy during booms vs. recessions was unclear as to whether asymmetries were driven by the convexity of the supply curve or by financial market frictions. The empirical framework proposed here allows us to identify directly both whether financial market frictions affect the transmission of monetary policy shocks and whether financial deepening mitigates the adverse effects of shocks as the financial accelerator mechanism suggests. ${ }^{5}$ To carry out our investigation, we augment our model with an interaction term between monetary policy shock and financial depth measures, which acts as a proxy of financial frictions, and estimate the resulting model by an instrumental variable Markov regime switching (MRS) framework, as suggested by Spagnolo, Psaradakis and Sola (2005). This framework allows us to examine the asymmetric effects of monetary policy shocks in conjunction with the role that financial depth plays, while the instrumental variable approach helps us to overcome endogeneity problems that may exist in our model.

Our investigation utilizes two separate financial depth measures. Our first measure is defined as the ratio of credits by financial intermediaries to the private sector with respect to GDP. The second measure is the ratio of claims on the non-financial private sector to total domestic credit (excluding credit to money banks). To gauge the effects of monetary policy shocks on real output, we have used three proxies. First, we follow a conventional approach to measuring monetary policy shocks by using the actual changes in the Federal funds rate as a policy measure. ${ }^{6}$ However, Romer and Romer (2004) have shown that the actual changes in the Federal funds rate could underestimate the impact of monetary policy on output growth, as this measure may have been contaminated by the endogenous movements of the interest rate and the expected actions of the Federal Reserve (Fed). To address these difficulties, Romer and Romer (2004) proposed an alternative measure by regressing the intended fund rate changes on the Fed's internal forecast of inflation and of real economic activity. In our case, rather than directly implementing the model that Romer and Romer (2004) used to generate monetary policy shocks, we modify it such that in one case the model's parameters are allowed to be time-variant and in the other case the parameters are allowed to be time-varying with regime switching. This modification to the original model was essential because there is substantial evidence that monetary policy has

\footnotetext{
${ }^{5}$ Peersman and Smets (2005), using industry level data from seven Euro area countries, implement a two step modelling approach in order to provide support for the financial accelerator mechanism. However, they do not examine how changes in financial deepening affect the asymmetries in monetary policy over the business cycle.

${ }^{6}$ See, for instance, Garcia and Schaller (2002).
} 
become more forward-looking; failure to account for structural breaks in the data could lead to biased results in evaluating the impact of monetary policy shocks. ${ }^{7}$

Our findings can be summarized as follows. We first show that monetary policy has a regime-dependent impact on output growth. In particular, we show that adverse monetary policy shocks exert a significant influence on output growth during recessions, yet this effect is not significant during expansions. We then provide evidence that financial depth significantly mitigates the impact of these adverse shocks during recessions: the total impact of adverse monetary policy shocks on output growth becomes much milder in recessions, and even diminishes with the deepening of the financial markets. This makes sense; firms mostly suffer from financial frictions during periods of recessions, so deeper financial markets could help firms to raise funds even in hard times. We carried out the analysis using quarterly US data over the period 1971:q1-2011:q4. We also estimated the model over 1971:q1-2008:q2, excluding the period that followed the collapse of the Lehman Brothers on the basis that the framework of monetary policy changed substantially after this episode. Results from this subsample also support to our claims.

The paper is structured as follows. Section II provides a review of the empirical literature. Section III introduces the data, the model and the methodology that is utilized in our analysis. Section IV presents the empirical results. Section V concludes the study.

\section{Brief literature review}

There exists a substantial body of literature examining the impact of monetary policy on the real economy. Although vector autoregressive (VAR) models have been the main workhorse of researchers in examining the effects of monetary policy on the economy, more recently several researchers have begun to implement stochastic volatility (SV) models to investigate the transmission of shocks on real variables. ${ }^{8} \mathrm{SV}$ models, although attractive, have a tendency to anticipate the changes in volatility before they actually happen in cases where the underlying process has discrete jumps. This arises due to the fact that these models favour small changes in the data over large ones. As Diebold (1986) argued, the SV model could severely bias estimates and invalidate inferences if abrupt shifts in the data were ignored. As a consequence, when the data present sudden regime shifts, it is advisable to use other approaches.

To this end, researchers have been using Markov regime switching models to examine the asymmetric effects of monetary policy on the economy. Using this methodology, it has been shown that monetary policy shocks exert asymmetric effects on the real economy over the course of the business cycle. For instance, Garcia and Schaller (2002), provided evidence that monetary policy in the US has larger effects during recessions than expansions. Using data from seven euro-area countries, Peersman and Smets $(2002,2005)$ have demonstrated that regional shocks have a more profound effect on output during recessions than expansions. Kaufmann (2002), using data from Austria provided evidence that the impact of monetary policy on output growth is significant and negative during economic

\footnotetext{
${ }^{7}$ See for instance Barakchian and Crowe (2013).

${ }^{8}$ See for instance Fernández-Villaverde and Rubio-Ramírez (2013), Mumtaz and Zanetti (2013), Mumtaz and Theodoridis (2015) and the references therein.
} 
recessions, and insignificant during periods of normal or above average output growth. Dolado and María-Dolores (2006), implementing a multivariate Markov switching model, showed that the effects of monetary policy on real output growth in the euro-area depend on the state of the business cycle.

The observation that adverse monetary policy shocks exert a significant impact on economic activities in recessions is also corroborated by Weise (1999), who used a logistic smooth transition vector autoregressive model to examine the asymmetries in monetary transmission mechanism. Similarly, using UK data and implementing a smooth transition regression model, Sensier, Osborn and Öcal (2002) showed that monetary policy is more powerful in recessions than in expansions. Lo and Piger (2005), also using an unobservedcomponent model with regime switching and time varying transition probabilities, argued that changes in monetary policy have stronger real effects in the US during recessions than in expansions. Subsequently, Höppner, Melzer and Neumann (2008) confirmed the asymmetry of monetary policy over the course of the US business cycle by applying a time-varying coefficient VAR model. However, none of these studies have considered the role that financial deepening may play in assessing the asymmetric effect of monetary policy shocks on the economy during the course of the business cycle.

When we turn to examine the importance of financial market frictions on growth and productivity, we find a deep and expanding body of literature starting with the work of Bernanke and Gertler (1989). The empirical evidence, based on aggregate data, suggests that the development and deepening of financial markets enable firms to have easier access to external funds, thereby dampening the impact of negative shocks on the economy. Similar conclusions have been provided by researchers examining industry or firm-level data. For instance, Raddatz (2006) found that greater financial depth significantly reduced output volatility, especially in sectors which require a high level of liquidity. He argues that his results provide strong evidence of the importance of financial development in reducing output fluctuations. This is because an increase in financial market depth improves the ability of the financial system to provide liquidity to firms during recessions.

Separately, Ferreira da Silva (2002), using data from 40 countries over the period 19601997, showed that countries with deeper financial markets experience smoother business cycles. In the same spirit, Beck et al. (2012) have found that a higher level of financial innovation not only increases a country's growth opportunities, capital and GDP per capita growth, but also increases the growth rates of industries which are more dependent on external finance and financial innovation. Cowan and Raddatz (2013) have shown that firms that operate in sectors which need high external financing contract relatively more following sharp reductions in international capital flows. Taken together, these studies suggest that financial deepening plays an important role in relation to the smooth functioning of the economy and the transmission of shocks.

In the rest of the paper, using more than 40 years of quarterly data, we empirically examine the asymmetric effects of monetary policy during booms and recessions while considering the role of financial deepening in the transmission of monetary policy shocks. To this end, we implement an instrumental variable Markov regime switching framework. The use of an instrumental variable approach is essential in a study such as this, as the results may be affected by endogeneity due to the potential correlation between the explanatory variables and the disturbance term. 


\section{Data and methodology}

\section{Data}

We have conducted our analysis using quarterly US data over the period 1971:q1-2011:q4. The data are obtained from the International Financial Statistics (IFS) of the International Monetary Fund (IMF). We have measured output growth $\left(y_{t}\right)$ in period $t$, by the first difference of the logarithm of the real GDP index $(2005=100)$, IFS line $99 \mathrm{~b}$. In what follows, we discuss the remaining variables that we employ in our analysis.

\section{Measuring financial depth}

We use two different measures to determine the extent of the financial depth $\left(f d_{t}\right)$ in the economy. These measures allow us to evaluate the amount of credit given to the private sector. Our first financial depth measure $(F D 1)$, which is proposed by Levine, Loayza and Beck (2000), is the ratio of credits by financial intermediaries to the private sector with respect to GDP. This measure has been constructed as $0.5 \times\left[\frac{F(t)}{P_{\text {end }}(t)}+\frac{F(t-1)}{P_{\text {end }}(t-1)}\right] / \frac{G D P(t)}{P_{\text {ave }}(t)}$. In this measure, $F$ denotes quarterly credit loaned by deposit money banks and other financial institutions to the private sector (IFS lines $22 \mathrm{~d}+42 \mathrm{~d}$ ), $P_{\text {end }}$ is end-of period quarterly consumer price index (CPI), $P_{\text {ave }}$ is the average CPI for the quarter and GDP is seasonally adjusted nominal quarterly gross domestic product (IFS line 99b). Quarterly CPI is extracted from IFS line 64. Specifically, this depth measure includes only those credits issued by banks and other financial intermediaries. Following Levine et al. (2000), we measure the items on the financial intermediary balance sheets at the end of the period; however, GDP is measured over the whole period. Thus, the end-of-period items in financial intermediary balance sheets are deflated by the end of period CPI, while the GDP series is deflated by the average CPI for the period.

Our second financial depth measure (FD2), proposed by King and Levine (1993), is the ratio of claims on the non-financial private sector to total domestic credit (excluding credit to money banks). Total domestic credit is composed of claims on central government, on state and local governments, on public non-financial corporations and on the non-financial private sector. Claims on the non-financial private sector are extracted from IFS line $32 \mathrm{~d}$ and total domestic credit is taken from IFS lines $32 \mathrm{a}$ through $32 \mathrm{f}$ excluding $32 \mathrm{e}$. This proxy provides information on the percentage of credit allocated to private firms in the economy. It therefore measures the extent to which credit is allocated to the private rather than the public sector.

\section{Measuring monetary policy shocks}

A quick survey of the literature shows that researchers use the VAR methodology heavily when examining the effects of monetary policy. However, given that the policy makers have become more forward-looking over the years, as Barakchian and Crowe (2013) have demonstrated, the identification of structural shocks in VAR models has become a more difficult task. ${ }^{9}$ This is due to the fact that, when agents react to expected variables that

\footnotetext{
${ }^{9}$ For more see, among others, Leeper, Sims and Zha (1996), Christiano, Eichenbaum and Evans (1999).
} 
are not observed by the econometricians, non-fundamentalness emerges. ${ }^{10}$ Benati and Surico (2009) have also argued that there is a fundamental disconnect between what is actually structural within a dynamic stochastic general equilibrium (DSGE) model and what is considered to be structural in the structural VAR representation implied by the same DSGE model. At the very least, recent research has shown that comparison of structural VAR (SVAR) estimates with those from a DSGE model is not straightforward and that caution must be exercised when comparing the two models. ${ }^{11}$

Given these concerns, we employed three different proxies to gauge the stance of the monetary policy. As a first measure of monetary policy shocks, we used the first difference of the logarithm of the Federal Funds rate $\left(m p_{t}\right)$, IFS line $60 \mathrm{~b}$. This is a simple and a conventional measure, which has been previously used by many researchers to gauge monetary policy shocks. ${ }^{12}$ However, this approach is subject to two main shortcomings. First, Federal funds rate often moves endogenously with changes in economic conditions. Such endogenous movements lead to biased estimates of the impact of monetary policy on the target variables. For instance, an endogenous response of the fund rates to economic activities might lead one to underestimate the impact of monetary policy on the real variables. ${ }^{13}$ Furthermore, when analysing the effects of monetary policy on economic growth and on inflation, one should measure the variation in the policy rates that is orthogonal to the Fed's forecast of future output and inflation.

To circumvent these hurdles, we have adopted the Romer and Romer (2004) approach and have generated two additional monetary policy shocks by introducing time-varying parameters and regime shifts into their model. The second proxy, which we used to gauge monetary policy shocks, therefore allowed for time-variation in all parameters of the eighteen variables in Romer and Romer (2004). The third monetary policy shock allowed for the parameters of the underlying model to be time-varying with regime shifts while we only use those variables that are significant in construction of the second proxy. ${ }^{14}$

\section{Methodology}

In order to examine the role of financial frictions when evaluating the asymmetric impact of monetary policy on real output, we implemented a Markov switching framework. In implementing this approach one has to be careful against the possibility of endogeneity of the monetary policy and the financial depth measures, which we have used as explanatory variables in the output growth equation. In this case, the use of standard maximum likelihood approach in estimating a regime switching model would yield inconsistent parameter estimates as a result of the within-regime correlation between the regressors and the

\footnotetext{
${ }^{10} \mathrm{~A}$ model is non-fundamental when structural shocks cannot be recovered by current and past observations; see Hansen and Sargent (1991).

${ }^{11}$ For further discussion see Kilian (2012).

${ }^{12}$ See, for instance, Sims (1992), Bernanke and Mihov (1998) and Garcia and Schaller (2002).

${ }^{13}$ See Romer and Romer (2004).

${ }^{14}$ Romer and Romer (2004) measured monetary policy shocks using a reaction function, in which the desired Federal funds target rate was the dependent variable and the right-hand side variables included the level of the desired Federal funds target prior to the FOMC meeting, and the forecasts of 17 series (the current quarter of unemployment, eight forecasts for the real GDP growth and the GDP deflator) taken from the Greenbook.
} 
disturbance term. To overcome the endogeneity problem in this case, we followed an approach suggested by Spagnolo et al. (2005) and estimated the following system of equations for output growth and the instrumenting equations for monetary policy and for financial depth:

$$
y_{t}=\mu_{s_{t}}+\sum_{i=1}^{j} \gamma_{i, s_{t}} y_{t-i}+\beta_{s_{t}} \widehat{m p}_{t-1}+\varphi_{s_{t}} \widehat{f d}_{t}+\eta_{s_{t}} \widehat{m p}_{t-1} \times \widehat{f d}_{t-1}+\sigma_{s_{t}} \varepsilon_{t}
$$

where

$$
\begin{aligned}
& \mu_{s_{t}}=\left[\mu_{0}\left(1-s_{t}\right)+\mu_{1} s_{t}\right], \gamma_{i, s_{t}}=\left[\gamma_{i, 0}\left(1-s_{t}\right)+\gamma_{i, 1} s_{t}\right], \\
& \beta_{s_{t}}=\left[\beta_{0}\left(1-s_{t}\right)+\beta_{1} s_{t}\right], \varphi_{s_{t}}=\left[\varphi_{0}\left(1-s_{t}\right)+\varphi_{1} s_{t}\right], \\
& \eta_{s_{t}}=\left[\eta_{0}\left(1-s_{t}\right)+\eta_{1} s_{t}\right], \text { and } \sigma_{s_{t}}=\left[\sigma_{0}\left(1-s_{t}\right)+\sigma_{1} s_{t}\right] \\
& m p_{t-1}=\kappa_{s_{t}}+\sum_{i=1}^{k} \delta_{i, s_{t}} y_{t-i-1}+\sum_{i=1}^{l} \phi_{i, s_{t}} m p_{t-i-1}+\theta_{s_{t}} \xi_{t}
\end{aligned}
$$

where

$$
\begin{gathered}
\kappa_{s_{t}}=\kappa_{0}\left(1-s_{t}\right)+\kappa_{1} s_{t}, \delta_{i, s_{t}}=\delta_{i, 0}\left(1-s_{t}\right)+\delta_{i, 1} s_{t}, \\
\phi_{i, s_{t}}=\phi_{i, 0}\left(1-s_{t}\right)+\phi_{i, 1} s_{t} \text { and } \theta_{s_{t}}=\theta_{0}\left(1-s_{t}\right)+\theta_{1} \\
f d_{t}=\alpha_{s_{t}}+\sum_{i=1}^{m} \lambda_{i, s_{t}} f d_{t-i}+\chi_{s_{t}} s_{t}
\end{gathered}
$$

where

$$
\begin{aligned}
& \alpha_{s_{t}}=\alpha_{0}\left(1-s_{t}\right)+\alpha_{1} s_{t}, \lambda_{i, s_{t}}=\lambda_{i, 0}\left(1-s_{t}\right)+\lambda_{i, 1} s_{t} \text { and } \\
& \chi_{s_{t}}=\chi_{0}\left(1-s_{t}\right)+\chi_{1} s_{t}
\end{aligned}
$$

The state variable, $s_{t}$, is a homogenous first order Markov chain on $\{0,1\}$ with transition probabilities:

$$
\begin{aligned}
& q=P\left[s_{t}=0 \mid s_{t-1}=0\right], \\
& p=P\left[s_{t}=1 \mid s_{t-1}=1\right] .
\end{aligned}
$$

In this system, equation (1) models real output growth $\left(y_{t}\right)$, equation (2) models monetary policy $\left(m p_{t-1}\right)$ and equation (3) models financial depth $\left(f d_{t}\right)$, while all explanatory variables have state dependent coefficients. The disturbance terms in equations (1-3) are captured by $\epsilon_{t}, \xi_{t}$ and $\varsigma_{t}$, respectively. The first equation includes the lags of the dependent variable, a measure of expected financial depth $\left(\widehat{f d}_{t}\right)$, and, to capture the observation that output growth reacts to changes in monetary policy with a lag, the first lag of expected monetary policy $\left(\widehat{m p}_{t-1}\right)$. The output growth equation also includes an interaction term between the first lag of financial depth and the first lag of monetary policy measure: $\left(\widehat{m p}_{t-1} \times \widehat{f d}_{t-1}\right)$. The interaction term is of key importance, as it allows us to examine whether the effects of monetary policy on output growth are dependent on the extent of the financial depth. In particular, significant coefficients over high or low growth states can help us to determine whether financial depth dampens or intensifies the impact of monetary policy on real output over the course of the business cycle. The fitted value 
of monetary policy, $\widehat{m p}_{t-1}=E\left[m p_{t-1} \mid s_{t-1}, \Omega_{t-1}\right]$, is obtained from equation (2), where $s$ denotes the unobserved state variable and $\Omega_{t-1}$ denotes the information set available at time $t-1$. In the same way, the fitted value of financial depth, $\widehat{f d}_{t}=E\left[f d_{t} \mid s_{t}, \Omega_{t}\right]$, is obtained from instrumenting equation (3).

Equation (2) is a reduced-form model for monetary policy shocks, $m p_{t-1}$, which is assumed to respond asymmetrically to the second lag of output and to the lagged dependent variable. Equation (3) models financial depth as an autoregressive process in which the associated parameters depend on the state of the economy. ${ }^{15}$

To estimate this model we have used a recursive algorithm, which is explained in Hamilton (1994). This process yields a sample likelihood function which can be maximized numerically with respect to $v=\left(\mu_{0}, \mu_{1}, \gamma_{1,0}, \gamma_{1,1}, \gamma_{2,0}, \gamma_{2,1}, \ldots, \gamma_{j, 0}, \gamma_{j, 1}, \beta_{0}, \beta_{1}, \varphi_{0}, \varphi_{1}, \eta_{0}, \eta_{1}\right.$, $\sigma_{0}, \sigma_{1}, \kappa_{0}, \kappa_{1}, \delta_{1,0}, \delta_{1,1}, \delta_{2,0}, \delta_{2,1}, \ldots, \delta_{j, 0}, \delta_{j, 1}, \phi_{1,0}, \phi_{1,1}, \phi_{2,0}, \phi_{2,1}, \ldots, \phi_{j, 0}, \phi_{j, 1} \theta_{0}, \theta_{1}, \alpha_{0}, \alpha_{1}, \lambda_{i, 0}$, $\left.\lambda_{i, 1}, \lambda_{2,0}, \lambda_{2,1}, \ldots, \lambda_{j, 0}, \lambda_{j, 1}, \chi_{0}, \chi_{1}\right)$ subject to the constraint that $p$ and $q$ lie in the open unit interval. In consequence, we can write the conditional probability density function of $w_{t}=\left(y_{t}, m p_{t}, f d_{t}\right)$ given the state $s_{t}$ and the history of the system:

$$
\begin{aligned}
\operatorname{pdf}\left(w_{t} \mid s_{t}, w_{t-1}, \ldots, w_{1} ; v\right) \\
=\frac{1}{\sqrt{2 \pi} \sigma_{s_{t}}} \exp \left[-\frac{1}{2}\left(\frac{y_{t}-\mu_{s_{t}}-\sum_{j=1}^{J} \gamma_{j, s_{t}} y_{t-j}-\beta_{s_{t}} \widehat{m p}_{t-1}-\varphi_{s_{t}} \widehat{f d}_{t}-\eta_{s_{t}} \widehat{m p}_{t-1} \times \widehat{f d}_{t-1}}{\sigma_{s_{t}}}\right)^{2}\right] \\
\quad \times \frac{1}{\sqrt{2 \pi} \theta_{s_{t}}} \exp \left[-\frac{1}{2}\left(\frac{m p_{t-1}-\kappa_{s_{t}}-\sum_{k=1}^{K} \delta_{k, s_{t}} y_{t-k-1}-\sum_{l=1}^{L} \phi_{l, s_{t}} m p_{t-l-1}}{\theta_{s_{t}}}\right)^{2}\right] \\
\quad \times \frac{1}{\sqrt{2 \pi} \chi_{s_{t}}} \exp \left[-\frac{1}{2}\left(\frac{f d_{t}-\alpha_{s_{t}}-\sum_{i=1}^{M} \lambda_{i, s_{t}} f d_{t-i}}{\chi_{s_{t}}}\right)^{2}\right]
\end{aligned}
$$

Here $\widehat{m p}_{t-1}=\widehat{\kappa}_{s_{t}}+\sum_{k=1}^{K} \widehat{\delta}_{k, s_{t}} y_{t-k-1}+\sum_{l=1}^{L} \widehat{\phi}_{l, s_{t}} m p_{t-l-1}$ and $\widehat{f d}_{t}=\widehat{\alpha}_{s_{t}}+\sum_{i=1}^{M} \widehat{\lambda}_{i, s_{s}} f d_{t-i}$ are obtained from the state-dependent instrumenting equations for $m p_{t-1}$ and $f d_{t}$ as shown in equations (2) and (3).

Note that the system of equations in (1-4) assumes that the unobserved state variables of GDP growth, monetary policy and financial depth measures are synchronized. Before carrying out the empirical analysis, we first examined the interrelations between the unobserved states of the variables in the model. Based on this investigation, we chose a model to examine the asymmetric effects of monetary policy on output growth while taking into account the role of financial depth. This will be discussed in the next section 'Modelling the unobserved states'.

\section{Modelling the unobserved states}

Our empirical model examines the asymmetric effects of monetary policy during booms and recessions taking into account the role of financial market depth. However, before estimating equations $1-4$, it is important to examine the interrelations between the

\footnotetext{
${ }^{15}$ The set of instruments used has been selected on the basis of the statistical significance of variables. We used a general model in which each equation included the same indicators. Specifically, we initially estimated a fourth order VAR model. We then selected those indicators which were statistically significant.
} 
unobserved states of the variables in the model. Without such an investigation, it would be unclear whether the unobserved states of the variables are in the same or different phases with respect to one another and we would not be able to construct an appropriate switching model. To illustrate the problem at hand, let us examine the interaction between the unobserved states of $y_{t}$ and $f d_{t}$. Consider a $2 \times 1$ vector $z_{t}=\left[y_{t}, f d_{t}\right]^{\prime}$ such that ${ }^{16}$

$$
z_{t}=\mu_{s t}+\sum_{i=1}^{p} \Phi_{i} z_{t-i}+v_{t}
$$

where $v_{t}=\left[u_{t}^{y}, u_{t}^{f d}\right]^{\prime}$ is a Gaussian process with mean zero and positive-definite variance covariance matrix $\Sigma ;\left\{s_{t}\right\}$, the unobserved state of $z$, is modelled by the unobserved states of $s_{t}^{y}$ and $s_{t}^{f d}$ as a linear homogenous four-state Markov process with ${ }^{17}$

$$
\begin{gathered}
s_{t}^{z}=1 \text { if } s_{t}^{f d}=1 \text { and } s_{t}^{y}=1 \\
s_{t}^{z}=2 \text { if } s_{t}^{f d}=2 \text { and } s_{t}^{y}=1 \\
s_{t}^{z}=3 \text { if } s_{t}^{f d}=1 \text { and } s_{t}^{y}=2 \\
s_{t}^{z}=4 \text { if } s_{t}^{f d}=2 \text { and } s_{t}^{y}=2
\end{gathered}
$$

Under these conditions, there are four possible models that can be examined. Model $A$ considers the case in which the unobserved states associated with both variables $\left(s_{t}^{y}\right.$ and $\left.s_{t}^{f d}\right)$ are independent. To capture this, we constructed the following transition probability matrix for $s_{t}^{z}$ :

$$
P_{y f d}^{A}=P^{y} \otimes P^{f d}=\left[\begin{array}{cccc}
p_{11}^{y} p_{11}^{f d} & p_{11}^{y} p_{21}^{f d} & p_{21}^{y} p_{11}^{f d} & p_{21}^{y} p_{21}^{f d} \\
p_{11}^{y} p_{12}^{f d} & p_{11}^{y} p_{22}^{f d} & p_{21}^{y} p_{12}^{f d} & p_{21}^{y} p_{22}^{f d} \\
p_{12}^{y} p_{11}^{f d} & p_{12}^{y} p_{21}^{f d} & p_{22}^{y} p_{11}^{f d} & p_{22}^{y} p_{21}^{f d} \\
p_{12}^{y} p_{12}^{f d} & p_{12}^{y} p_{22}^{f d} & p_{22}^{y} p_{12}^{f d} & p_{22}^{y} p_{22}^{f d}
\end{array}\right]
$$

Model $B$, which is suggested by Schwert (1989) and Campbell, Kim and Lettau (1998), considers the case of perfect synchronization of the states of both variables such that $s_{t}^{y}=s_{t}^{f d}$. In this model the unobserved state variable $s_{t}^{z}$ follows a two-state Markov process with the transition probability matrix:

$$
P_{y f d}^{B}=\left[\begin{array}{cccc}
p_{11}^{y} p_{11}^{f d} & 0 & 0 & p_{21}^{y} p_{21}^{f d} \\
0 & 0 & 0 & 0 \\
0 & 0 & 0 & 0 \\
p_{12}^{y} p_{12}^{f d} & 0 & 0 & p_{22}^{y} p_{22}^{f d}
\end{array}\right]
$$

It should be noted that Model B has fewer parameters than Model A, as the number of states are reduced from four to two. ${ }^{18}$ This reduction in states occurs because Model B imposes the restriction that $p_{i j}^{y}=p_{i j}^{f d}$; that is, the unobserved states of both variables are perfectly

\footnotetext{
${ }^{16}$ The model can be easily extended to account for three variables where $z_{t}=\left[y_{t}, f d_{t}, m p_{t}\right]^{\prime}$. However, for the sake of clarity, we have limited our examination to the case where $z_{t}$ includes only two variables. If $z_{t}$ were to be three dimensional then the latent variable $s_{t}^{z}$ would follow an 8-state Markov chain.

${ }^{17}$ For more details see Phillips (1991), Hamilton and Lin (1996) and Sola, Spagnolo and Spagnolo (2007).

${ }^{18}$ This implies that Models A and B are non-nested because, under the reduction of states, the two state model suffers from the standard nuisance parameter problem.
} 
synchronized. In consequence, one may expect to observe a worse fit when Model B is implemented in place of Model A. However, Model B allows for dependence between $y$ and $f d$ through the common dependence of the unobserved $s_{t}^{y}$. This relaxes the assumption of independence maintained in Model A and might lead to an improved fit. ${ }^{19}$

An alternative model, Model $C$, can be constructed for the case in which the unobserved state of financial depth measure leads the unobserved state of output growth (i.e. $s_{t}^{y}=s_{t-1}^{f d}$ ). In this case, the transition probability matrix of $s_{t}^{z}$ takes the form:

$$
P_{y f d}^{C}=\left[\begin{array}{cccc}
p_{11}^{y} p_{11}^{f d} & 0 & p_{21}^{y} p_{11}^{f d} & 0 \\
p_{11}^{y} p_{12}^{f d} & 0 & p_{21}^{y} p_{12}^{f d} & 0 \\
0 & p_{12}^{y} p_{21}^{f d} & 0 & p_{22}^{y} p_{21}^{f d} \\
0 & p_{12}^{y} p_{22}^{f d} & 0 & p_{22}^{y} p_{22}^{f d}
\end{array}\right]
$$

In this model, expectations about the future state of output affect the current state of financial depth.

Finally, if financial depth reacts to expectations concerning a variable other than output, then the unobserved state of output might lead the unobserved state of financial depth measure $\left(s_{t}^{f d}=s_{t-1}^{y}\right)$. Hence, in model $D$, the transition probability matrix of $s_{t}^{z}$ will be:

$$
P_{y f d}^{D}=\left[\begin{array}{cccc}
p_{11}^{y} p_{11}^{f d} & p_{11}^{y} p_{21}^{f d} & 0 & 0 \\
0 & 0 & p_{21}^{y} p_{12}^{f d} & p_{21}^{y} p_{22}^{f d} \\
p_{12}^{y} p_{11}^{f d} & p_{12}^{y} p_{21}^{f d} & 0 & 0 \\
0 & 0 & p_{22}^{y} p_{12}^{f d} & p_{22}^{y} p_{22}^{f d}
\end{array}\right]
$$

Using models $A, B, C$ and $D$, it is possible to examine the interrelations between the unobserved states of the associated variables. However, prior to implementing any of the above models, it is useful to estimate univariate MRS models for each variable and to compare their associated filter probabilities. This exercise helps in determining whether or not the unobserved states of the variables are synchronized. After this experiment, the models discussed in this section can be implemented. We present our findings in section IV.

\section{Other econometric issues}

To implement the Markov regime switching framework, the data must exhibit regime shifts. We follow Hansen (1992a, 1996) to test for regime switching. Note that the null hypothesis of linearity against the alternative of a Markov regime switching cannot be tested directly using a standard likelihood ratio (LR) test. This is owing to the fact that under the null of linearity the parameters of transition probabilities are unidentified and the scores with respect to parameters of interest are identically zero. Under such circumstances the information matrix is singular. We, therefore apply Hansen's standardized likelihood ratio test, which requires an evaluation of the likelihood function across a grid of different values for the transition probabilities. ${ }^{20}$

\footnotetext{
${ }^{19}$ See Hamilton and Lin (1996) along these lines.

${ }^{20}$ In accordance with the suggestion of one of our referees, we modified the Hansen routine to check whether equation (1) has two regimes. Results from this test are qualitatively similar to those presented in Table 1 and are available from the authors upon request.
} 


\section{Empirical analysis}

In this section, we first provide evidence that all variables in equations 1-3 follow a Markov regime switching process. Second, we estimate univariate MRS models for each of the variables to determine the synchronicity of the unobserved states of the variables that we employ in our model. Third, we estimate equations 1-4 using one of the models that we discussed in section 'Modelling the unobserved states'. For all cases, we present results for the full model. However, having observed that the level of financial depth does not have a significant effect on output growth, we have excluded it from our latter models. We have estimated the model for the full sample as well as up to the period before the collapse of Lehman Brothers to avoid the postcrisis period during which the Fed changed its approach to stimulating the economy. We gauge monetary policy shocks using the change in interest rates and two additional policy measures to check for the robustness of our empirical results. The results are similar for both sample periods, both financial depth measures and all three monetary policy shock measures.

\section{Preliminary tests}

Table 1 shows that the Hansen test rejects the null of linearity for the change in interest rate and the first measure of financial development. However, the null of linearity for GDP growth and the second measure of financial depth cannot be rejected. This might be due to the low power of the test when the model accounts for autoregressive dynamics. To further investigate the presence of regime switching, we implemented structural break tests proposed by Hansen (1992b), Andrews (1993), and Andrews and Ploberger (1994) for the output growth equation (1), as we employed both financial depth measures. We applied the same tests for the instrumenting equation of the financial depth measures, equation (3), as well. The null hypothesis for these tests is that parameters are stable while the alternative is that there is evidence of a one-time change at the break point. The Hansen (1992b) tests (see Table 2) indicate that there is parameter instability in the output growth equation and the instrumenting equation for financial depth.

The second issue that must be resolved is the synchronicity of the unobserved states of the variables in the model. Only after examining the synchronicity of the states of the

TABLE 1

\begin{tabular}{lllll}
\multicolumn{5}{c}{ Hansen test results } \\
\hline & $y$ & $m p$ & FD1 & FD2 \\
\hline Standardized LR & 0.699 & 6.344 & 0.839 & 2.163 \\
$M=0$ & 0.581 & 0.000 & 0.468 & 0.080 \\
$M=1$ & 0.560 & 0.000 & 0.459 & 0.059 \\
$M=2$ & 0.553 & 0.000 & 0.446 & 0.055 \\
$M=3$ & 0.549 & 0.000 & 0.436 & 0.050 \\
$M=4$ & 0.542 & 0.000 & 0.423 & 0.053 \\
\hline
\end{tabular}

Notes: Financial depth 1 (FD1) is the ratio of credits by financial intermediaries to the private sector with respect to GDP. Financial depth 2 (FD2) is the ratio of claims on the non-financial private sector to total domestic credit (excluding credit to money banks). 
TABLE 2

Stability tests for output growth and financial depth variables

\begin{tabular}{lc}
\hline Panel A: Stability tests for output growth equation \\
\multicolumn{2}{l}{ Using financial depth measure FD1 } \\
Hansen (1992a,b) & $1.596^{*}$ \\
Andrews (1993) & 6.898 \\
Andrews and Ploberger (1994) & 1.616 \\
Using financial depth measure FD2 \\
Hansen (1992a,b) & $1.912^{* *}$ \\
Andrews (1993) & 11.546 \\
Andrews and Ploberger (1994) & 3.314
\end{tabular}

Panel B: Stability tests for financial depth; instrumenting equation

Financial depth measure: FD1

Hansen (1992a,b) 0.674*

Andrews (1993) $\quad 5.587$

Andrews and Ploberger (1994) 1.108

Financial depth measure: FD2

Hansen (1992a, b) $\quad 0.863^{* *}$

Andrews (1993) 3.679

Andrews and Ploberger (1994) $\quad 0.369$

Notes: $*, * *, * * *$ denote significance at the $10 \%, 5 \%$ and $1 \%$ levels. Each entry depicts the estimated test statistics associated with the listed reference. See notes to Table 1.

variables that we use in the model can we determine which of the four models discussed in section 'Modelling the unobserved states' could be used for our analysis. Following an approach similar to that in Hamilton and Lin (1996), as preliminary check, we estimated a univariate Markov switching model for each variable and generated the associated filter probabilities. We then superimposed the filter probability of output growth on the filter probabilities of financial depth and monetary policy measures and displayed them on separate panels in Figure 1. The top and bottom panels show that the filter probability of output growth (see Filter_Y) is similar to that of the monetary policy measure (see Filter_DIR) and the second financial depth measure (see Filter FD2). Equipped with this evidence, we use Model B to examine the relationship between output growth, monetary policy shock and the second financial depth measure. However, the middle panel demonstrates that the filter probability of the first financial depth (see Filter FD1) differs from that of output growth for almost the first ten years of the sample. Therefore, when using the first financial depth measure, we must use one of the remaining three models that we discussed in section 'Modelling the unobserved states'.

To assess the extent to which the unobserved states of the first financial depth measure (FD1) is aligned with those of the output growth and the proxy for monetary policy, we estimated Model A and plotted the filter probabilities for each of the possible four states in Figure 2, (States 1-4). States 1 and 4 depict the filter probabilities when the unobserved state variables are synchronized. Similarly, States 2 and 3 show the filter probabilities when the unobserved state variables are not synchronized. Looking at each panel, we see that although the filter probabilities of State 2 and State 3 are low, they are not close to zero. In Figure 3, the upper graph shows the sum of the probabilities when the unobserved 

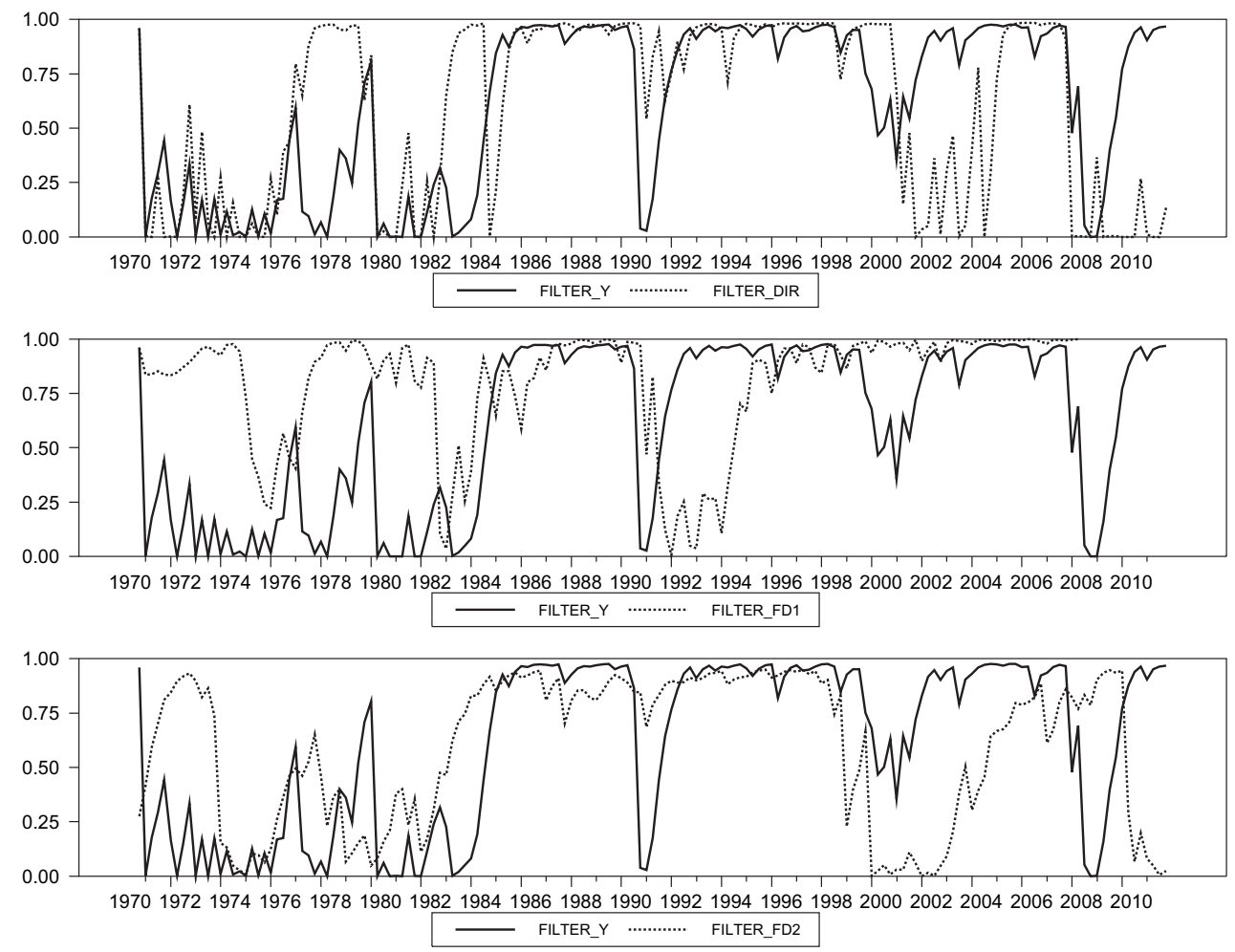

Figure 1. Filter probabilities from a single variable Markov switching model

states of both variables are in the same phase, while the lower graph shows the sum of the probabilities when the unobserved states of both variables are in differing phases. The lower plot in Figure 3 gives the impression that the sum of the filter probabilities of States 2 and 3 is substantially high approximately for the first and the last 10 years of the sample. This observation suggests that the unobserved states of $F D 1$ differ from the other variables in the model. As a result, we estimated all four models for $F D 1$ and allow the data to determine the best model.

\section{Results for the full sample}

Table 3 presents estimates for equations 1-4 when we estimate Models A, B, C and D for the first proxy of financial depth, $F D 1 .{ }^{21} \mathrm{By}$ inspecting the coefficient estimates, we see that in all cases the state dependent growth rate $\mu_{0}$ is greater than $\mu_{1}$. Hence, State zero captures the high growth regime and State 1 captures the low growth regime. We can also observe that the impact of monetary policy shocks $(\beta)$ is negative and this impact significantly varies between different states in each Model. This is suggestive of the asymmetric impact of monetary policy shocks between regimes. Furthermore, we also observe that the interaction term between the proxy for monetary policy shocks and financial depth is positive and

\footnotetext{
${ }^{21}$ To facilitate the presentation of our results, we withheld the estimates for the instrumenting equations; these are available upon request from the authors.
} 

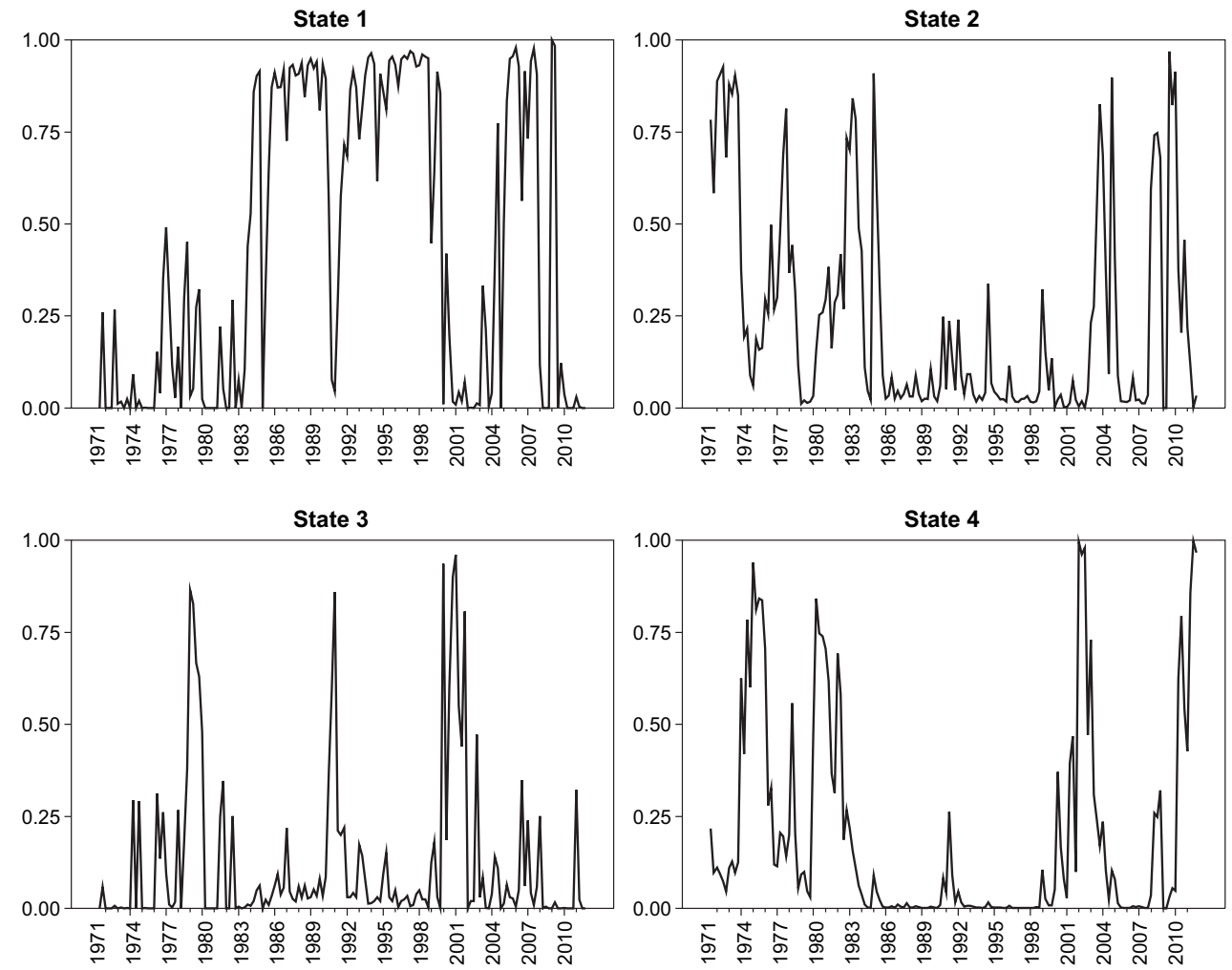

Figure 2. Filter probabilities for $F D 1$ using Model A

significant in the low growth state $\left(\eta_{1}\right)$ for all four Models. Nevertheless, the level effect of financial depth on output growth $(\varphi)$ is always insignificant.

In the light of the results presented in Table 3, we re-estimated the model after excluding the level effect of financial depth. The results for the restricted model are given in Table 4. The estimates of the state dependent growth rate $\mu_{0}$ are positive and significant whereas the estimates of $\mu_{1}$ are not significantly different from zero. This clearly suggests that State zero captures the high growth regime and State 1 captures the low growth regime. Furthermore, the other coefficients in the model take the expected signs and significance. Specifically, we observed that monetary policy has a negative and significant impact only in the low growth regime, suggesting the presence of asymmetric impact of monetary policy shocks on output growth. When we inspect the interaction coefficient $(\eta)$ between monetary policy and financial depth, we see that it is positive and significant only in the low growth regime. This result confirms the conjecture that financial depth dampens the negative effect of adverse monetary policy shocks on economic activity during recessions.

These observations are true for all four models; however, Model A appears to perform better than Models B, C and D. Henceforth, the role of the first financial depth measure, FD1, is discussed in the context of Model A.

Next, we estimate equations 1-4 using Model B for the second financial depth proxy, $F D 2{ }^{22}$ The results are presented in Table 5. The first two columns of the Table give the

\footnotetext{
${ }^{22}$ Recall that in Model B the unobserved states of all variables in the model are synchronized.
} 
(a)

Total Probability of Being in Common States

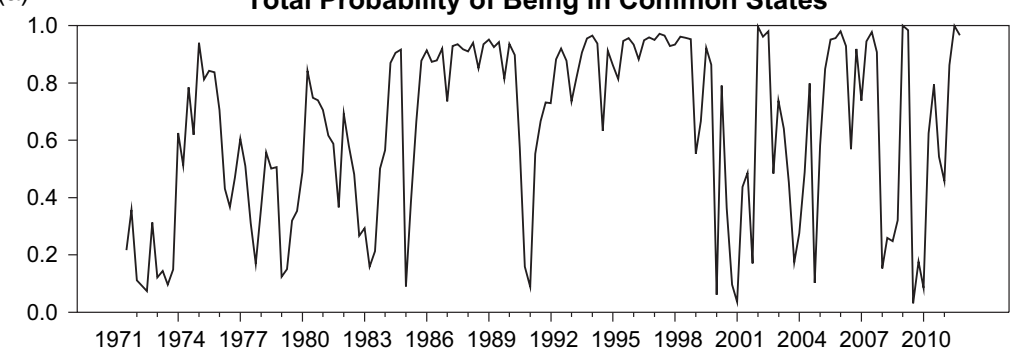

(b)

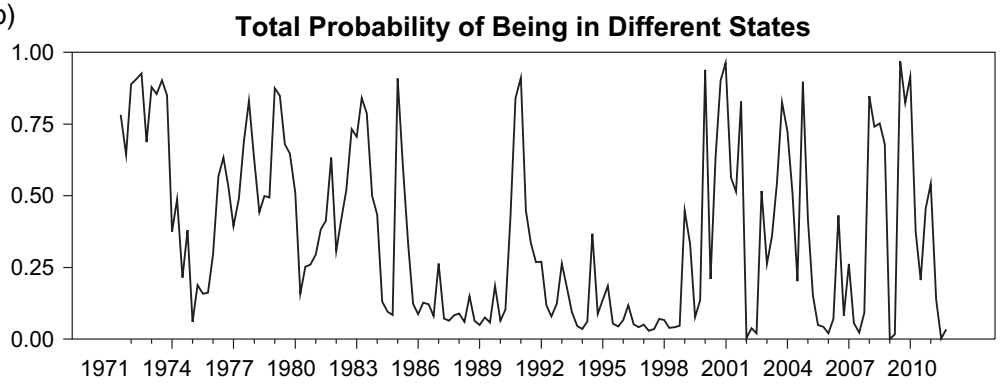

Figure 3. Total probability of being in (a) common states (b) different states

Notes: The upper (lower) graph plots the sum of probabilities of States 1 and 4 (2 and 3) for FD1 using the data in Figure 2.

parameter estimates and the standard errors when the level effect of financial depth is included in the model. The remaining two columns give the estimates and their standard errors when the level effect is removed.

As in Model A, State zero captures the high growth regime and State 1 captures the low growth regime. However, an inspection of the first two columns shows that most of the coefficient estimates are not significant. When we turn to the latter two columns, which exclude the level effect of financial depth, we see that the coefficient estimates demonstrate the expected sign and significance. Specifically, we observe that the effect of monetary policy $(\beta)$ is significantly negative only in the low growth state, indicating the presence of asymmetry. We also observe that the interaction coefficient becomes significantly positive in the low growth regime.

\section{Results for the pre-financial crisis period: 1971:q1-2008:q2}

In order to evaluate whether these results are robust to the exclusion of observations from the period after the collapse of Lehman Brothers, we re-estimate our models with a focus on the pre-financial crisis period between 1971:q1 and 2008:q2. ${ }^{23}$ The results presented in Table 6 are largely similar to our observations for the full sample. The first two columns present the results for the first financial depth measure, while the latter two columns give the results for the second financial depth measure. As in Tables 3-5 the state dependent growth rate $\mu_{0}$ is positive and significant for State zero and insignificant for State 1; hence, State zero denotes the high growth regime and State 1 denotes the low growth regime. We found that monetary

\footnotetext{
${ }^{23}$ After the collapse of Lehman Brothers, the Fed changed its approach to stimulate the economy, as the use of conventional monetary policy tools were not effective.
} 
TABLE 3

Model selection for FD1 for the full model: Asymmetric effect of monetary policy on output growth (1971:q1-2011:q4)

\begin{tabular}{|c|c|c|c|c|c|c|c|c|}
\hline & \multicolumn{2}{|l|}{ Model A } & \multicolumn{2}{|l|}{ Model B } & \multicolumn{2}{|l|}{ Model C } & \multicolumn{2}{|l|}{ Model D } \\
\hline & Estimates & $S E$ & Estimates & $S E$ & Estimates & $S E$ & Estimates & $S E$ \\
\hline$\mu_{0}$ & 0.003 & 0.003 & 0.004 & 0.003 & 0.003 & 0.003 & 0.004 & 0.003 \\
\hline$\gamma_{11}$ & 0.156 & 0.091 & $0.296^{* *}$ & 0.125 & $0.294 * * *$ & 0.112 & $0.293 * * *$ & 0.110 \\
\hline$\gamma_{12}$ & $0.366^{* * *}$ & 0.110 & $0.245^{*}$ & 0.131 & $0.290 * *$ & 0.124 & $0.293 * *$ & 0.131 \\
\hline$\beta_{0}$ & -0.012 & 0.024 & 0.013 & 0.024 & 0.019 & 0.038 & 0.013 & 0.063 \\
\hline$\eta_{0}$ & 0.003 & 0.013 & -0.009 & 0.013 & -0.017 & 0.027 & -0.011 & 0.043 \\
\hline$\varphi_{0}$ & 0.001 & 0.002 & 0.000 & 0.002 & 0.000 & 0.002 & 0.000 & 0.002 \\
\hline$\sigma_{0}$ & $0.004 * * *$ & 0.000 & $0.004 * * *$ & 0.000 & $0.004 * * *$ & 0.000 & $0.004 * * *$ & 0.000 \\
\hline$\mu_{1}$ & 0.002 & 0.005 & 0.000 & 0.007 & 0.001 & 0.005 & 0.000 & 0.005 \\
\hline$\gamma_{21}$ & $0.407 * * *$ & 0.135 & $0.307 * * *$ & 0.114 & $0.271 * * *$ & 0.103 & $0.279 * * *$ & 0.104 \\
\hline$\gamma_{22}$ & 0.495 & 0.368 & $0.56^{*}$ & 0.296 & $0.683^{* *}$ & 0.325 & $0.674 * *$ & 0.319 \\
\hline$\beta_{1}$ & $-0.194 * *$ & 0.084 & $-0.242 * *$ & 0.095 & $-0.123 * * *$ & 0.044 & $-0.127 * * *$ & 0.045 \\
\hline$\eta_{1}$ & $0.095 * *$ & 0.044 & $0.125^{* *}$ & 0.052 & $0.050 * *$ & 0.020 & $0.053 * * *$ & 0.020 \\
\hline$\varphi_{1}$ & -0.002 & 0.002 & -0.001 & 0.004 & -0.002 & 0.003 & -0.001 & 0.003 \\
\hline$\sigma_{1}$ & $0.001 * * *$ & 0.001 & $0.009 * * *$ & 0.001 & $0.009 * * *$ & 0.001 & $0.009 * * *$ & 0.001 \\
\hline$p_{0}$ & $0.910 * * *$ & 0.042 & $0.918 * * *$ & 0.046 & $0.981 * * *$ & 0.014 & $0.969 * * *$ & 0.019 \\
\hline$q_{0}$ & $0.899 * * *$ & 0.054 & $0.910 * * *$ & 0.042 & $0.969 * * *$ & 0.019 & $0.981 * * *$ & 0.014 \\
\hline$p_{1}$ & $0.953 * * *$ & 0.029 & - & - & - & - & - & - \\
\hline$q_{1}$ & $0.905 * * *$ & 0.070 & - & - & - & - & - & - \\
\hline Likelihood & 1035.800 & & 1024.600 & & 999.570 & & 997.860 & \\
\hline
\end{tabular}

Notes: $y_{t}=\mu_{s_{t}}+\sum_{i=1}^{j} \gamma_{i, s_{t}} y_{t-i}+\beta_{s_{t}} \widehat{m p}_{t-1}+\varphi_{s_{t}} \widehat{f d}_{t}+\eta_{s_{t}} \widehat{m p}_{t-1} \times \widehat{f d}_{t-1}+\sigma_{s_{t}} \varepsilon_{t}$, where $y_{t}, \widehat{m p}_{t-1}$ and $\widehat{f d}_{t}$ denote output growth, expected monetary policy shock and expected financial depth, respectively. $\varepsilon_{t}$ is the error term. $*, * *, * * *$ denote significance at the $10 \%, 5 \%$ and $1 \%$ levels. Model A assumes that the unobserved state of $f d$ is independent from that of $y$. Model B assumes that the unobserved state of $f d$ and $y$ are perfectly synchronized. Model $\mathrm{C}$ assumes that the unobserved state of $f d$ leads that of $y$. Model D assumes that the unobserved state of and $y$ leads that of $f d$. FD1 measures the ratio of credit by financial intermediaries to the private sector with respect to GDP.

policy had asymmetric effects during the period preceding the financial crisis for the first financial depth measure, but not for the second. In our assessment of the role of financial depth in the transmission of monetary policy, we have observed that the interaction term takes a positive and significant coefficient in the low growth state for both financial depth measures. The positive sign associated with the interaction term suggests that financial depth dampens the impact of adverse monetary policy shocks during recessions.

Overall, using two different financial depth measures, and two different samples (full data and pre-financial crisis period) we have drawn two conclusions from our investigation. First, monetary policy shocks have an asymmetric impact on output growth over the course of the business cycle. The effect of monetary policy is significant in recessions (the low growth regime), but not during expansions (the high growth regime). Second, financial deepening dampens the impact of adverse monetary policy shocks on output growth in low growth regimes.

\section{Additional robustness checks based on alternative monetary policy measures}

We have provided additional results by estimating the model for two Romer and Romer (2004) type of monetary policy shock measures, which allow for time-variation. The first 
TABLE 4

Model selection for FD1 without the level effect: Asymmetric effects of monetary policy on output growth (1971:q1-2011:q4)

\begin{tabular}{|c|c|c|c|c|c|c|c|c|}
\hline & \multicolumn{2}{|l|}{ Model A } & \multicolumn{2}{|l|}{ Model B } & \multicolumn{2}{|l|}{ Model C } & \multicolumn{2}{|l|}{ Model D } \\
\hline & Estimates & $S E$ & Estimates & $S E$ & Estimates & $S E$ & Estimates & $S E$ \\
\hline$\mu_{0}$ & $0.004 * * *$ & 0.001 & $0.004 * * *$ & 0.001 & $0.004 * * *$ & 0.001 & $0.003 * * *$ & 0.001 \\
\hline$\gamma_{11}$ & $0.172 *$ & 0.097 & $0.303 * *$ & 0.117 & $0.293 * * *$ & 0.113 & $0.294 * * *$ & 0.110 \\
\hline$\gamma_{12}$ & $0.354 * * *$ & 0.101 & $0.222 *$ & 0.117 & $0.285^{* *}$ & 0.128 & $0.296^{* *}$ & 0.119 \\
\hline$\beta_{0}$ & -0.020 & 0.029 & -0.030 & 0.039 & 0.015 & 0.049 & 0.014 & 0.039 \\
\hline$\eta_{0}$ & 0.007 & 0.015 & 0.014 & 0.022 & -0.014 & 0.033 & -0.013 & 0.027 \\
\hline$\sigma_{0}$ & $0.005 * * *$ & 0.000 & $0.005 * * *$ & 0.000 & $0.004 * * *$ & 0.000 & $-0.004 * * *$ & 0.000 \\
\hline$\mu_{1}$ & -0.001 & 0.004 & -0.004 & 0.005 & -0.002 & 0.004 & -0.002 & 0.003 \\
\hline$\gamma_{21}$ & $0.397 * * *$ & 0.132 & $0.270 * * *$ & 0.122 & 0.279 & 0.104 & $0.282 * * *$ & 0.103 \\
\hline$\gamma_{22}$ & 0.488 & 0.351 & 0.771 & 0.417 & $0.687 * *$ & 0.330 & $0.677^{* *}$ & 0.323 \\
\hline$\beta_{1}$ & $-0.211^{* *}$ & 0.086 & $-0.157^{* *}$ & 0.072 & $-0.133 * * *$ & 0.045 & $-0.132 * * *$ & 0.045 \\
\hline$\eta_{1}$ & $0.109 * * *$ & 0.043 & $0.067 * *$ & 0.033 & $0.057 * * *$ & 0.020 & $0.057 * * *$ & 0.019 \\
\hline$\sigma_{1}$ & $0.010 * * *$ & 0.001 & $0.010 * * *$ & 0.001 & $0.009 * * *$ & 0.001 & $0.009 * * *$ & 0.001 \\
\hline$p_{0}$ & $0.915^{* * *}$ & 0.037 & $0.897 * * *$ & 0.054 & $0.981 * * *$ & 0.014 & $0.981^{* * *}$ & 0.014 \\
\hline$q_{0}$ & $0.910 * * *$ & 0.046 & $0.913 * * *$ & 0.039 & $0.969 * * *$ & 0.019 & $0.969 * * *$ & 0.019 \\
\hline$p_{1}$ & $0.962 * * *$ & 0.024 & - & - & - & - & - & - \\
\hline$q_{1}$ & $0.940 * * *$ & 0.047 & - & - & - & - & - & - \\
\hline Likelihood & $1,034.200$ & & $1,009.300$ & & 999.130 & & 997.770 & \\
\hline
\end{tabular}

Note: See notes to Table 3.

measure is generated by a model that allows for time varying parameters, while the other is derived from a model that allows for time varying parameters with regime shifts. The results for $F D 2$ are presented in Table 7.

The first two columns of the table present the coefficient estimates and their standard variations for the second monetary policy shock measure (RR-TVP), which has been obtained from a time-varying parameter model. The latter two columns present results for the third monetary policy shock measure (RR-TVP MRS), which has been obtained from a model in which the parameters are time-varying and the volatility is regime dependent.

Overall, observations from Table 7 confirm our earlier findings. Here, too, State zero denotes high growth regime and State 1 denotes low growth regime. Furthermore, regardless of the type of monetary policy shock, we can see that the effect of monetary policy $(\beta)$ is only significant during the low growth state. When we go on to examine the role of financial depth, we see that the interaction coefficient $(\eta)$ is positive and significant during the low growth regime only. These results provide further support for our earlier findings.

\section{The full impact of monetary policy}

So far, we have shown that adverse monetary policy shocks exert a significant negative impact on output growth only during low growth states and that financial deepening dampens these effects. These results are intuitively plausible and highlight the significant role that financial frictions play in the transmission of monetary policy. However, the evidence we have presented thus far does not capture the full impact of monetary policy on output 
TABLE 5

Asymmetric effect of monetary policy on output growth for FD2 with and without the level effects (1971:q1-2011:q4)

\begin{tabular}{lclccc}
\hline & \multicolumn{2}{c}{ FD2 (Model B) } & & \multicolumn{2}{c}{ FD2 (Model B) } \\
\cline { 2 - 3 } & Estimates & $S E$ & & Estimates & $S E$ \\
\hline$\mu_{0}$ & 0.068 & 0.052 & & $0.005^{* * *}$ & 0.001 \\
$\gamma_{11}$ & $0.335^{* *}$ & 0.147 & & 0.121 & 0.100 \\
$\gamma_{12}$ & 0.356 & 0.407 & & $0.328^{* * *}$ & 0.112 \\
$\beta_{0}$ & -0.695 & 0.467 & -0.081 & 0.184 \\
$\eta_{0}$ & 0.778 & 0.549 & & 0.088 & 0.215 \\
$\varphi_{0}$ & -0.087 & 0.063 & & - \\
$\sigma_{0}$ & $0.009^{* * *}$ & 0.001 & & $0.005^{* * *}$ & 0.001 \\
$\mu_{1}$ & 0.041 & 0.035 & & -0.007 & 0.009 \\
$\gamma_{21}$ & 0.085 & 0.189 & & $0.352^{* * *}$ & 0.134 \\
$\gamma_{22}$ & 0.260 & 0.197 & & 0.507 & 0.555 \\
$\beta_{1}$ & -0.116 & 0.597 & & $-1.473^{* *}$ & 0.591 \\
$\eta_{1}$ & 0.130 & 0.692 & & $1.680^{* *}$ & 0.649 \\
$\varphi_{1}$ & -0.044 & 0.042 & & - & - \\
$\sigma_{1}$ & $0.005^{* * *}$ & 0.001 & & $0.009^{* * *}$ & 0.001 \\
$p_{0}$ & $0.873^{* * *}$ & 0.046 & & $0.864^{* * *}$ & 0.064 \\
$q_{0}$ & $0.854^{* * *}$ & 0.115 & $0.873^{* * *}$ & 0.047 \\
\hline Likelihood & $1,261.8$ & & $1,266.100$ & \\
\hline
\end{tabular}

Notes: $y_{t}=\mu_{s_{t}}+\sum_{i=1}^{j} \gamma_{i, s_{t}} y_{t-i}+\beta_{s_{t}} \widehat{m p}_{t-1}+\varphi_{s_{t}} \widehat{f d}_{t}+\eta_{s_{t}} \widehat{m p}_{t-1} \times$ $\widehat{f d}_{t-1}+\sigma_{s_{t}} \varepsilon_{t}$, where $y_{t}, \widehat{m p}_{t-1}$ and $\widehat{f d}_{t}$ denote output growth, expected monetary policy shock and expected financial depth, respectively. $\varepsilon_{t}$ is the error term. $* * *, * * *$ denote significance at the $10 \%, 5 \%$ and $1 \%$ levels. Model B assumes that the unobserved states of all variables are perfectly correlated. FD2 is the ratio of claims on the non-financial private sector to total domestic credit (excluding credit to money banks).

growth over the course of the business cycle, nor the full role of financial depth in the transmission of monetary policy shocks. Hence, we use equation (1) and evaluate the total derivative of output growth with respect to monetary policy for each state

$$
d y_{t} / d \widehat{m p}_{t-1}=\left[\widehat{\beta}_{0}\left(1-s_{t}\right)+\widehat{\beta}_{1} s_{t}\right]+\left[\widehat{\eta}_{0}\left(1-s_{t}\right)+\widehat{\eta}_{1} s_{t}\right] \widehat{f d}_{t-1}^{*}
$$

at various levels of financial depth, $\widehat{f d}_{t-1}^{*}$, while the parameters, $\widehat{\beta}_{i}$ and $\widehat{\eta}_{i}$, are set to their point estimates. The estimates $\hat{\beta}_{i}$ and $\hat{\eta}_{i}$ capture the direct and indirect impact of monetary policy on output growth, respectively. The index $s_{t}$ denotes the states of the economy where State zero represents the low growth regime and State 1 represents the high growth regime. $\widehat{f d} d_{t-1}^{*}$ refers to a particular level of financial depth at which we compute the derivative including the 10th, 25th, 50th, 75th, and 90th percentiles. Using the parameter estimates and the associated standard deviations for the first financial depth measure in columns 1 and 2 of Table 4, we compute the full impact of monetary policy on output growth along with the associated standard errors. ${ }^{24}$ In Figure 4, we plot the point estimates that we give in Table (8), along with their corresponding 95\% confidence interval.

\footnotetext{
${ }^{24}$ We have withheld the results for the other financial depth measure as the conclusions are similar.
} 
TABLE 6

Asymmetric effect of monetary policy on output growth: Pre-financial crisis period (1971:q1-2008:q2)

\begin{tabular}{lcllll}
\hline & \multicolumn{2}{c}{ FD1 (Model A) } & & \multicolumn{2}{c}{ FD2 (Model B) } \\
\cline { 2 - 3 } \cline { 5 - 6 } & Estimates & SE & & Estimates & $S E$ \\
\hline$\mu_{0}$ & $0.004^{* *}$ & 0.0014 & & $0.005^{* * *}$ & 0.002 \\
$\gamma_{11}$ & $0.185^{*}$ & 0.103 & & 0.09 & 0.107 \\
$\gamma_{12}$ & $0.359^{* * *}$ & 0.111 & & $0.315^{* * *}$ & 0.102 \\
$\beta_{0}$ & -0.019 & 0.0578 & & 0.064 & 0.169 \\
$\eta_{0}$ & 0.008 & 0.0372 & & -0.09 & 0.208 \\
$\sigma_{0}$ & $0.005^{* * *}$ & 0.00041 & & $0.004^{* * *}$ & 0 \\
$\mu_{1}$ & -0.001 & 0.0044 & & -0.11 & 0.307 \\
$\gamma_{21}$ & $0.289^{* *}$ & 0.130 & 0.245 & 0.127 \\
$\gamma_{22}$ & 0.602 & 0.391 & & 6.375 & 16.526 \\
$\beta_{1}$ & $-0.188^{* *}$ & 0.0845 & & -3.276 & 4.253 \\
$\eta_{1}$ & $0.098^{* *}$ & 0.0476 & & $2.430^{* *}$ & 1.094 \\
$\sigma_{1}$ & $0.009^{* * *}$ & 0.00092 & $0.009^{* * *}$ & 0.001 \\
$p_{0}$ & $0.970^{* * *}$ & 0.0251 & $0.890^{* * *}$ & 0.056 \\
$q_{0}$ & $0.970^{* * *}$ & 0.0409 & $0.896^{* * *}$ & 0.046 \\
$p_{1}$ & $0.930^{* * *}$ & 0.0509 & & - \\
$q_{1}$ & $0.935^{* * *}$ & 0.0352 & & - \\
\hline Likelihood & 972.91 & & $1,199.3$ & - \\
\hline
\end{tabular}

Note: See notes to Tables 3 and 5.

TABLE 7

Asymmetric effect of monetary policy on output growth: Results for RR type monetary policy shocks applied to FD2 using Model B

\begin{tabular}{lccccc}
\hline Proxy type & RR-TVP & & \multicolumn{2}{c}{ RR-TVP MRS } \\
\cline { 2 - 3 } \cline { 5 - 6 } & Estimates & $S E$ & & Estimates & $S E$ \\
\hline$\mu_{0}$ & $0.006^{* * *}$ & 0.001 & & $0.005^{* * *}$ & 0.002 \\
$\gamma_{11}$ & $0.608^{* * *}$ & 0.128 & & $0.308^{* *}$ & 0.143 \\
$\gamma_{12}$ & $-0.227^{*}$ & 0.135 & & 0.015 & 0.072 \\
$\beta_{0}$ & -0.061 & 0.072 & -0.034 & 0.102 \\
$\eta_{0}$ & 0.089 & 0.091 & & 0.043 & 0.129 \\
$\sigma_{0}$ & $0.007^{* * *}$ & 0.001 & & $0.011^{* * *}$ & 0.001 \\
$\mu_{1}$ & $0.003^{* * *}$ & 0.001 & & $0.003^{* * *}$ & 0.001 \\
$\gamma_{21}$ & 0.115 & 0.080 & & $0.185^{* *}$ & 0.094 \\
$\gamma_{22}$ & $0.379^{* * *}$ & 0.083 & & $0.366^{* * *}$ & 0.092 \\
$\beta_{1}$ & $-0.179^{* *}$ & 0.074 & & $-0.167^{* *}$ & 0.078 \\
$\eta_{1}$ & $0.218^{* *}$ & 0.092 & & $0.215^{* *}$ & 0.098 \\
$\sigma_{1}$ & $0.005^{* * *}$ & 0.000 & & $0.004^{* * *}$ & 0.000 \\
$p$ & $0.869^{* * *}$ & 0.065 & $0.993^{* * *}$ & 0.008 \\
$q$ & $0.842^{* * *}$ & 0.067 & $0.990^{* * *}$ & 0.014 \\
\hline Likelihood & $1,090.2$ & & $1,082.7$ & \\
\hline
\end{tabular}

Notes: $*, * *, * * *$ denote significance at the $10 \%, 5 \%$ and $1 \%$ levels. RR-TVP denotes time-varying monetary policy shock measure. RR-TVP MRS denotes regime dependent monetary policy shock indicator accounting for Markov switching heteroscedasticity. 

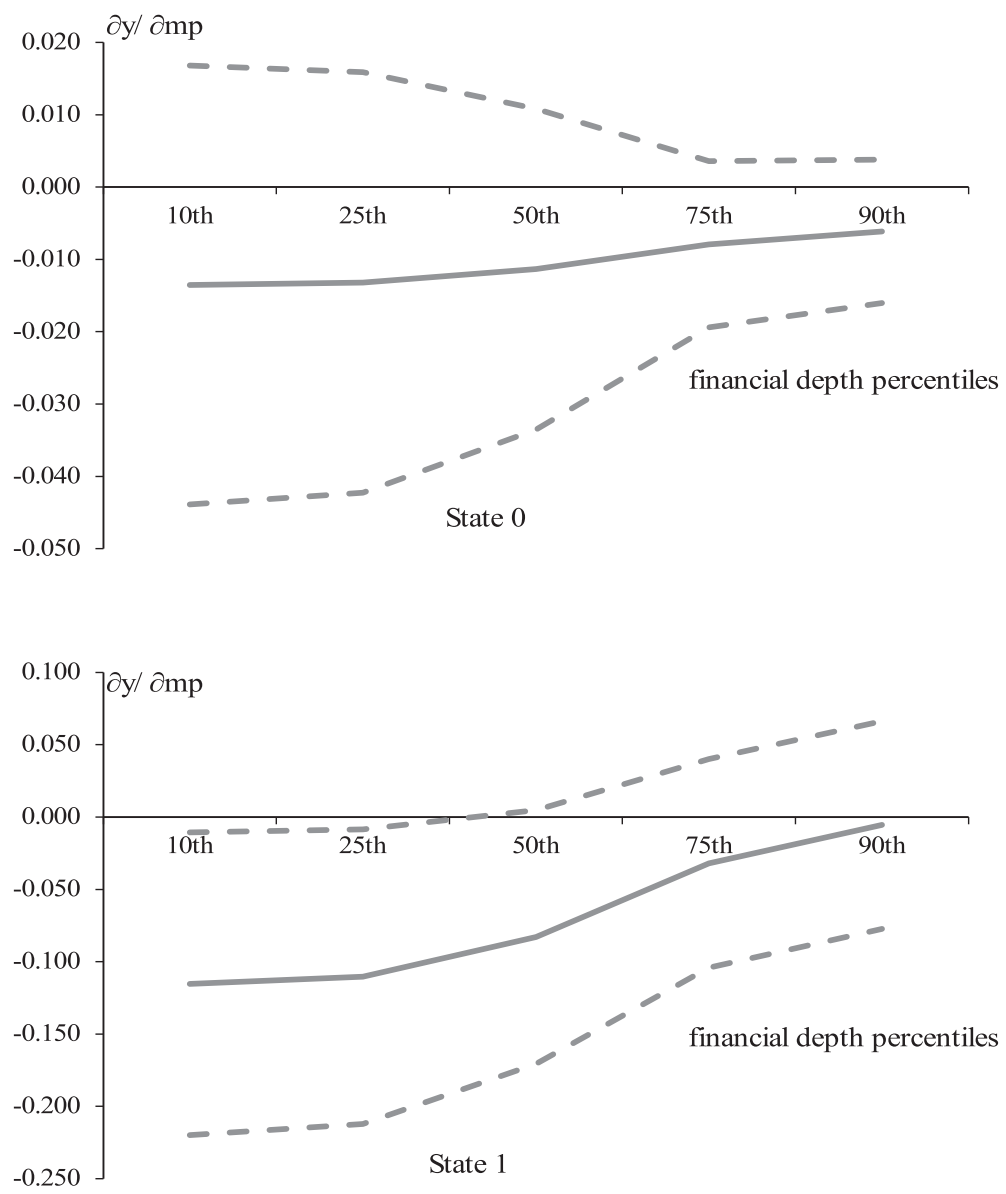

Figure 4. Full impact of an adverse monetary policy shock

Notes: The upper (lower) graph shows the full effect of an adverse monetary policy shock during a boom (recession) with respect to financial depth, FD1.

Panel A in Table (8) (see State zero, Figure 4) illustrates the full impact of an adverse monetary policy shock on output growth in expansions. When we inspect the Panel A, we see that the total impact of monetary policy on output growth is always negative but never significant, despite the financial deepening.

Inspecting Panel B in Table (8) (See State 1, Figure 4), we can see that an adverse monetary policy shock has a significant negative impact on output growth during recessions, when financial depth is shallow. However, this significant negative impact weakens and becomes insignificant with financial deepening. In other words, the impact of adverse monetary policy shocks would be stronger in recessions if the economy were to experience tight credit market conditions. In fact, when financial deepening is at approximately its median level, the effect of monetary policy on output growth becomes insignificant at the $5 \%$ level. This suggests that, when liquidity dries up during periods of low growth, the economy suffers considerably because of adverse monetary policy shocks, as businesses cannot sustain production and fixed investment in an environment where borrowing is compromised due to frictions in financial markets. 
TABLE 8

Full impact of monetary policy

\begin{tabular}{lrrrrr}
\hline & \multicolumn{1}{c}{$P 10$} & \multicolumn{1}{c}{ P25 } & \multicolumn{1}{c}{ P50 } & \multicolumn{1}{c}{ P75 } & \multicolumn{1}{c}{$P 90$} \\
\hline Panel A: State zero & & & & & \\
Financial depth & 0.886 & 0.932 & 1.184 & 1.654 & 1.899 \\
$\frac{\partial y}{\partial m p}$ & -0.014 & -0.013 & -0.011 & -0.008 & -0.006 \\
SE & 0.015 & 0.015 & 0.011 & 0.006 & 0.005 \\
$t$ statistic & -0.874 & -0.890 & -1.004 & -1.351 & -1.211 \\
Panel B: State 1 & & & & & \\
Financial depth & 0.886 & 0.932 & 1.184 & 1.654 & 1.899 \\
$\frac{\partial y}{\partial m p}$ & -0.115 & -0.110 & -0.083 & -0.032 & -0.005 \\
SE & 0.053 & 0.052 & 0.045 & 0.037 & 0.037 \\
$t$ statistic & -2.160 & -2.125 & -1.853 & -0.871 & -0.149 \\
\hline
\end{tabular}

Notes: Full impact of an adverse monetary policy shock is calculated for Financial Depth 1 (FD1). P denotes percentiles of financial depth at noted levels.

Our findings are particularly relevant in the light of events that followed the 2008/09 financial crisis. During this period, although central banks throughout the western economies injected billions of dollars into the system to keep financial markets afloat, businesses shed employees and cancelled or delayed their fixed capital investment expenditures as banks initially did not extend new credit owing to the uncertainty in the economic environment. Only after credit became more available, did the US economy move out of the recession. Overall, these recent observations support the view that monetary policy without financial deepening might be an insufficient force to push the economy out of recession.

\section{Conclusion}

In this study, we proposed an empirical framework to examine whether monetary policy has an asymmetric impact on output growth during booms and recessions and whether the asymmetric impact of monetary policy shocks is dependent on financial deepening. To avoid problems that may arise due to endogeneity of the explanatory variables, we implemented an instrumental variable Markov regime switching framework, as suggested in Spagnolo et al. (2005). The analysis is based on quarterly US data covering the period between 1971:q1 and 2011:q4.

Our analysis provides evidence that monetary policy has an asymmetric impact on output growth: restrictive monetary policies lead to a significant drop in output growth during recessions (low growth states), while such policies do not have any significant impact on output during booms (high growth states). When we examined the role of financial markets, we observed that financial depth plays a significant role in the transmission of monetary policy shocks, especially during recessions. In fact, our results provided evidence that, although tight monetary policy might have adverse effects on output growth during recessions, such effects diminish or even completely disappear with financial deepening. Overall, we have shown that our results are robust compared to alternative financial depth and monetary policy shock measures and different sample periods. 
The evidence we have presented has important policy implications, as it highlights the importance of financial deepening in the transmission of monetary policy shocks, especially in low growth states. More research on the interrelations between financial markets and monetary policy will help us to better understand the role that financial deepening plays on the impact of monetary policy.

\section{Acknowledgements}

We are grateful for constructive comments and suggestions from two anonymous reviewers of this journal and the editor. We are also grateful to A. Jackson, P. Nanos, J. Paez-Farrell, $\mathrm{K}$. Taylor and $\mathrm{K}$. Theodoridis for their specific comments as well as those of participants in the EcoMod Conference, 2015 Boston, USA, the 1st International Conference in Applied Theory, Macro and Empirical Finance; AMEF 2015, Thessaloniki, Greece, and the 2nd Annual Conference of the International Association for Applied Econometrics (IAAE). The standard disclaimer applies.

Final Manuscript Received: August 2016

\section{References}

Andrews, D. (1993). 'Tests for parameter instability and structural change with unknown change point', Econometrica, Vol. 61, pp. 821-856.

Andrews, D. and Ploberger, W. (1994). 'Optimal tests when a nuisance parameter is present only under the alternative', Econometrica, Vol. 62, pp. 1383-1414.

Ball, L. and Mankiw, N. (1994). 'Asymmetric price adjustment and economic fluctuations', Economic Journal, Vol. 104, pp. 247-261.

Ball, L. and Romer, D. (1990). 'Real rigidities and the non-neutrality of money', Review of Economic Studies, Vol. 57, pp. 183-203.

Barakchian, S. M. and Crowe, C. (2013). 'Monetary policy matters: evidence from new shocks data', Journal of Monetary Economics, Vol. 60, pp. 950-966.

Beck, T., Chen, T., Chen, L. and Song, F. (2012). Financial Innovation: The Bright and the Dark Sides, HKIMR Working Paper No. 05/2012.

Benati, L. and Surico, P. (2009). 'VAR analysis and the great moderation', American Economic Review, Vol. 99, pp. 1636-1652.

Bernanke, B. and Gertler, M. (1989). 'Agency costs, net worth, and business fluctuations', The American Economic Review, Vol. 79, pp. 14-31.

Bernanke, B. and Mihov, I. (1998). 'Measuring monetary policy', The Quarterly Journal of Economics, Vol. 113, pp. 869-902.

Bernanke, B., Gertler, M., and Gilchrist, S. (1996). 'The financial accelerator and the flight to quality', The Review of Economics and Statistics, Vol. 78, pp. 1-15.

Bernanke, B. S., Gertler, M. and Gilchrist, S. (1999). 'The financial accelerator in a quantitative business cycle framework', in J. B. Taylor and M. Woodford (eds), Handbook of Macroeconomics, Vol. 1, Chapter 21, Amsterdam: Elsevier, pp. 1341-1393.

Campbell, J. Y., Kim, S. and Lettau, M. (1998). Dispersion and Volatility in Stock Returns: An Empirical Investigation, CEPR Discussion Papers No. 1923.

Christiano, L. J., Eichenbaum, M. and Evans, C. L. (1999). 'Monetary policy shocks: what have we learned and to what end?', in Taylor J. B. and Woodford M. (eds), Handbook of Macroeconomics, Vol. 1, Chapter 2, Amsterdam: Elsevier, pp. 65-148.

Cover, J. (1992). 'Asymmetric effects of positive and negative money-supply shocks', The Quarterly Journal of Economics, Vol. 107, pp. 1261. 
Cowan, K. and Raddatz, C. (2013). 'Sudden stops and financial frictions: evidence from industry-level data', Journal of International Money and Finance, Vol. 32, pp. 99-128.

DeLong J. B. and Summers L. H., 1988. 'How Does Macroeconomic Policy Affect Output?', Brookings Papers on Economic Activity, Economic Studies Program, The Brookings Institution, Washington, Vol. 19, pp. 433-494.

Diebold, F. X. (1986). 'Modeling the persistence of conditional variances: a comment', Econometric Reviews, Vol. 5, pp. 51-56.

Dolado, J. J. and María-Dolores, R. (2006). 'State asymmetries in the effects of monetary policy shocks on output: some new evidence for the euro-area', in Milas C., Rothman P. and van Dijk, D. (eds), Nonlinear Time Series Analysis of Business Cycles, Vol. 276 of Contributions to Economic Analysis, Chapter 12, Leeds: Elsevier, pp. 311-331.

Fernández-Villaverde, J. and Rubio-Ramírez, J. (2013). 'Macroeconomics and volatility: data, models, and estimation', in Acemoglu D., Arellano M. and Dekel E. (eds), Vol. 3 of Advances in Economics and Econometrics: Theory and Applications, Tenth World Congress of the Econometric Society, Chapter 4, Cambridge: Cambridge University Press, pp. 137-183.

Ferreira da Silva, G. (2002). 'The impact of financial system development on business cycles volatility: crosscountry evidence', Journal of Macroeconomics, Vol. 24, pp. 233-253.

Garcia, R. and Schaller, H. (2002). 'Are the effects of monetary policy asymmetric?', Economic Inquiry, Vol. 40, pp. 102-119.

Hamilton, J. (1994). Time Series Analysis, Princeton, NJ: Princeton University Press.

Hamilton, J. D. and Lin, G. (1996). 'Stock market volatility and the business cycle', Journal of Applied Econometrics, Vol. 11, pp. 573-593.

Hansen, B. (1992a). 'The likelihood ratio test under nonstandard conditions: testing the Markov switching model of GNP', Journal of Applied Econometrics, Vol. 7, pp. 61-82.

Hansen, B. (1992b). 'Testing for parameter instability in linear models', Journal of Policy Modeling, Vol. 14, pp. $517-533$.

Hansen, B. (1996). 'Erratum: the likelihood ratio test under nonstandard conditions: testing the Markov switching model of GNP', Journal of Applied Econometrics, Vol. 11, pp. 195-198.

Hansen, L. and Sargent, T. (1991). 'Two difficulties in interpreting vector autoregressions', in Hansen L. and Sargent T. (eds), Rational Expectations Econometrics, Vol. 1 of Handbook of Macroeconomics, Chapter 2, Amsterdam: Westview Press, pp. 77-119.

Höppner, F., Melzer, C. and Neumann, T. (2008). 'Changing effects of monetary policy in the US-evidence from a time-varying coefficient VAR', Applied Economics, Vol. 40, pp. 2353-2360.

Karras, G. (1996). 'Why are the effects of money-supply shocks asymmetric? Convex aggregate supply or "pushing on a string"?', Journal of Macroeconomics, Vol. 18, pp. 605-619.

Kaufmann, S. (2002). 'Is there an asymmetric effect of monetary policy over time? A Bayesian analysis using Austrian data', Empirical Economics, Vol. 27, pp. 277-297.

Kilian, L. (2013). 'Structural vector autoregressions', in Hashimzade N. and Thornton M. (eds), Handbook of Research Methods and Applications in Empirical Macroeconomics, Vol. 1, Surrey: Edward Elgar, pp. $515-554$.

King, R. and Levine, R. (1993). 'Finance and growth: Schumpeter might be right', The Quarterly Journal of Economics, Vol. 108, pp. 717.

Leeper, E. M., Sims, C. A. and Zha, T. (1996). 'What does monetary policy do?', Brookings Papers on Economic Activity, Vol. 27, pp. 1-78.

Levine, R. (2005). 'Finance and growth: theory and evidence', in Aghion P. and Durlauf S. (eds.), Handbook of Economic Growth, Vol. 1, Chapter 12, Amsterdam: Elsevier, pp. 865-934.

Levine, R., Loayza, N. and Beck, T. (2000). 'Financial intermediation and growth: causality and causes', Journal of Monetary Economics, Vol. 46, pp. 31-77.

Lo, M. and Piger, J. (2005). 'Is the response of output to monetary policy asymmetric? Evidence from a regime-switching coefficients model', Journal of Money, Credit and Banking, Vol. 37, pp. 865-886.

Mumtaz, H. and Theodoridis, K. (2015). 'The international transmission of volatility shocks: an empirical analysis', Journal of European Economic Association, Vol. 13, pp. 512-533. 
Mumtaz, H. and Zanetti, F. (2013). 'The impact of the volatility of monetary policy shocks', Journal of Money, Credit and Banking, Vol. 45, pp. 535-558.

Papaioannou, E. (2007). Finance and Growth-A Macroeconomic Assessment of the Evidence from a European Angle, European Central Bank Working Paper Series No. 787.

Peersman, G. and Smets, F. (2002). 'Are the effects of monetary policy in the euro area greater in recessions than in booms?', in Mahadeva L. and Sinclair P. (eds), Monetary Transmission in Diverse Economies, Cambridge: Cambridge University Press, pp. 28-48.

Peersman, G. and Smets, F. (2005). 'The industry effects of monetary policy in the Euro area', The Economic Journal, Vol. 115, pp. 319-342.

Phillips, K. L. (1991). 'A two-country model of stochastic output with changes in regime', Journal of International Economics, Vol. 31, pp. 121-142.

Raddatz, C. (2006). 'Liquidity needs and vulnerability to financial underdevelopment', Journal of Financial Economics, Vol. 80, pp. 677-722.

Ravn, M. and Sola, M. (2004). 'Asymmetric effects of monetary policy in the United States', Review-Federal Reserve Bank of Saint Louis, Vol. 86, pp. 41-58.

Romer, C. D. and Romer, D. H. (2004). 'A new measure of monetary shocks: derivation and implications', American Economic Review, Vol. 94, pp. 1055-1084.

Schwert, G. W. (1989). 'Business cycles, financial crises, and stock volatility', Carnegie-Rochester Conference Series on Public Policy, Vol. 31, pp. 83-125.

Sensier, M., Osborn, D. R. and Öcal, N. (2002). 'Asymmetric interest rate effects for the UK real economy', Oxford Bulletin of Economics and Statistics, Vol. 64, pp. 315-339.

Sims, C. (1992). 'Interpreting the macroeconomic time series facts: the effects of monetary policy', European Economic Review, Vol. 36, pp. 975-1000.

Sola, M., Spagnolo, F. and Spagnolo, N. (2007). 'Predicting Markov volatility switches using monetary policy variables', Economics Letters, Vol. 95, pp. 110-116.

Spagnolo, F., Psaradakis, Z. and Sola, M. (2005). 'Testing the unbiased forward exchange rate hypothesis using a Markov switching model and instrumental variables', Journal of Applied Econometrics, Vol. 20, pp. 423-437.

Weise, C. (1999). 'The asymmetric effects of monetary policy: a nonlinear vector autoregression approach', Journal of Money, Credit and Banking, Vol. 31, pp. 85-108. 